\title{
Article \\ Myristic Acid Inhibits the Activity of the Bacterial ABC Transporter BmrA
}

\author{
Kristin Oepen ${ }^{1}$, Hüseyin Özbek ${ }^{2}$, Anja Schüffler ${ }^{2}{ }^{\circledR}$, Johannes C. Liermann ${ }^{1}$, Eckhard Thines ${ }^{2,3}$ \\ and Dirk Schneider $1,3, *$ (D) \\ 1 Department of Chemistry, Johannes Gutenberg-University, 55128 Mainz, Germany; \\ khackme@uni-mainz.de (K.O.); liermann@uni-mainz.de (J.C.L.) \\ 2 Institut für Biotechnologie und Wirkstoff-Forschung gGmbH (IBWF), 55128 Mainz, Germany; \\ Hozbek@tutanota.com (H.Ö.); schueffler@ibwf.de (A.S.); thines@uni-mainz.de (E.T.) \\ 3 Institute of Molecular Physiology, Johannes Gutenberg-University, 55128 Mainz, Germany \\ * Correspondence: Dirk.Schneider@uni-mainz.de; Tel.: +49-6131-39-25833
}

Citation: Oepen, K.; Özbek, H.; Schüffler, A.; Liermann, J.C.; Thines, E.; Schneider, D. Myristic Acid Inhibits the Activity of the Bacterial ABC Transporter BmrA. Int. J. Mol. Sci. 2021, 22, 13565. https://doi.org/ $10.3390 /$ ijms222413565

Academic Editors: Stathis Frillingos and Maria Botou

Received: 8 November 2021

Accepted: 14 December 2021

Published: 17 December 2021

Publisher's Note: MDPI stays neutral with regard to jurisdictional claims in published maps and institutional affiliations.

Copyright: (c) 2021 by the authors. Licensee MDPI, Basel, Switzerland. This article is an open access article distributed under the terms and conditions of the Creative Commons Attribution (CC BY) license (https:/ / creativecommons.org/licenses/by/ $4.0 /)$.

\begin{abstract}
ATP-binding cassette (ABC) transporters are conserved in all kingdoms of life, where they transport substrates against a concentration gradient across membranes. Some ABC transporters are known to cause multidrug resistances in humans and are able to transport chemotherapeutics across cellular membranes. Similarly, BmrA, the ABC transporter of Bacillus subtilis, is involved in excretion of certain antibiotics out of bacterial cells. Screening of extract libraries isolated from fungi revealed that the $\mathrm{C} 14$ fatty acid myristic acid has an inhibitory effect on the BmrA ATPase as well as the transport activity. Thus, a natural membrane constituent inhibits the BmrA activity, a finding with physiological consequences as to the activity and regulation of $\mathrm{ABC}$ transporter activities in biological membranes.
\end{abstract}

Keywords: ABC transporter; BmrA; membrane transport; myristic acid; inhibitor

\section{Introduction}

Membrane integral transport proteins mediate and control the translocation of essential compounds across biological membranes, involving the uptake and efflux of sugars, inorganic ions, nucleotides or drugs [1]. Primary active transporters use the energy gained via ATP hydrolysis for transport [1,2], and such transport ATPases are typically represented by ion pumps and ATP-binding cassette (ABC) transporters [2]. ABC transporters can be found in all kingdoms of life and they either import or export substrates against a concentration gradient. While, in bacteria, $\mathrm{ABC}$ importers and exporters can be found, eukaryotes mainly contain exporters [1,3]. Structurally, all ABC transporters consist of two nucleotide binding domains (NBDs) and two transmembrane domains (TMDs). The TMDs consist of $\alpha$-helix bundles that mediate the actual TM flux of the substrates, whereas ATP is hydrolyzed in the NBDs [3-5]. In contrast to the NBD, the sequences of the TMDs are typically less conserved and the TM topology can vary. The four domains of an $\mathrm{ABC}$ transporter can be part of a single polypeptide chain, or the transporter assembles from two to four individual subunits $[5,6]$. One TMD and one NBD can be fused to form a so-called half-transporter, which can either form a homodimeric (identical half-transporters) or assemble as a heterodimeric (different half-transporters) full-transporter $[1,3,7,8]$.

Many ABC transporters appear to be involved in bacterial multidrug resistances [9]. For example, in cervimycin $C$ resistant Bacillus subtilis colonies the bmrA gene, encoding an $\mathrm{ABC}$ half-transporter, was strongly overexpressed, which led to the assumption that BmrA (Bacillus multidrug-resistance ATP) is able to effectively transport this antibiotic out of the cell $[10,11]$. Besides cervimycin C, BmrA can transport a broad range of substrates, which include Hoechst 33342, doxorubicin as well as 7-aminoactinomycin D [11]. 
$\mathrm{BmrA}$, a homodimeric $\mathrm{ABC}$ transporter with a molecular mass of $64.9 \mathrm{kDa}$, is homologous to the bacterial ABC transporters LmrA and MsbA [6,12] as well as to the human P-glycoprotein $[3,11]$. In recent years, BmrA became a paradigm for studying ABC transporters, mostly due to the vast number of seemingly unrelated substrates as well as its homology to the human P-glycoprotein [11-13].

As BmrA is involved in excretion of certain antibiotics out of bacterial cells, we aimed at identifying small molecules which inhibit the BmrA transport activity and thus might be used to modulate the BmrA transport activity. Screening of extract libraries isolated from fungi revealed that the C14 fatty acid myristic acid has an inhibitory effect on the BmrA ATPase as well as the transport activity. Thus, BmrA "sleeps with the enemy", as a natural membrane constituent inhibits its activity, a finding with physiological consequences as to the activity and regulation of $\mathrm{ABC}$ transporter activities in biological membranes.

\section{Results}

\subsection{Myristic Acid Inhibits the ATPase Activity of the ABC Transporter BmrA}

In total, 448 fungal extracts were tested for an inhibitory effect on the BmrA ATPase activity and 22 were found to be active. One of the most promising candidates, the mycelial extract of strain IBWF 030-11, was selected for further characterization. To identify the natural product responsible for the inhibitory effect, the fungus was cultivated in a $20 \mathrm{~L}$ scale and the active principle was isolated. Based on NMR analysis, the isolated substance was identified as the C14 fatty acid myristic acid (Figure 1a), $0.25 \mathrm{mg}$ of which was isolated per $\mathrm{L}$ axenic fungus culture.

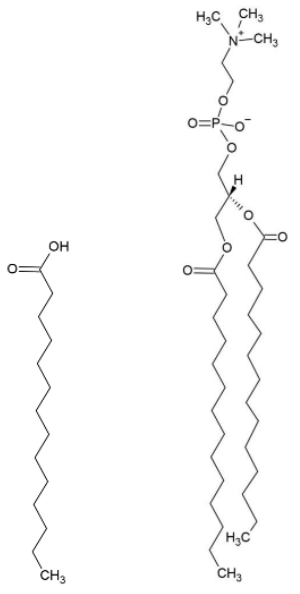

(a)

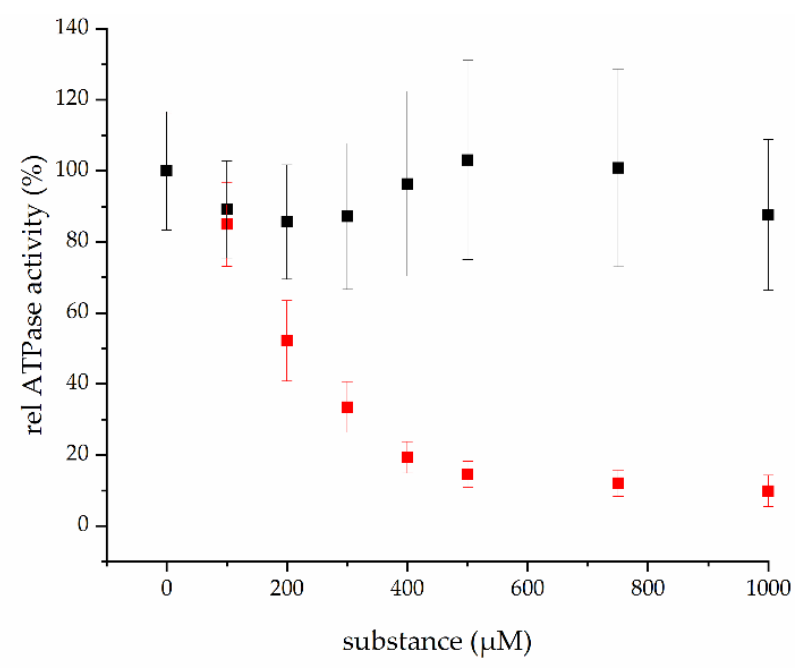

(c)

Figure 1. Inhibition of the BmrA ATPase activity by myristic acid. (a) Structure of the fatty acid myristic acid $\left(\mathrm{C}_{14} \mathrm{H}_{28} \mathrm{O}_{2}\right)$. (b) Structure of 1,2-dimyristoyl-sn-glycero-3-phosphocholine (DMPC), a membrane phospholipid containing two myristic acids as fatty acids. The structures were created using ChemSketch [14]. (c): Myristic acid ( $n \geq 6, \pm$ SEM; red) inhibits the in vitro ATPase activity of detergent solubilized BmrA, whereas the lipid 1,2-dimyristoyl-sn-glycero-3-phosphocholin (DMPC, $n=12, \pm$ SEM; black) does not.

To quantitatively evaluate the inhibitory potential of myristic acid, we next examined the in vitro ATPase activity of BmrA at increasing myristic acid concentrations (Figure 1c, red). The BmrA ATPase activity was determined in buffer containing myristic acid concentrations ranging from 0 to $1000 \mu \mathrm{M}$ to calculate the $\mathrm{IC}_{50}$ value, i.e., the substance concentration required to inhibit $50 \%$ of the protein's ATPase activity. The ATPase activity of BmrA in pure $5 \mathrm{mM}$ DDM was $1.0 \pm 0.16 \mu \mathrm{mol} / \mathrm{min}$ per $\mathrm{mg}$ protein, a value comparable to values previously determined under slightly different experimental conditions $[15,16]$. As expected in the presence of an inhibitor, the ATPase activity constantly decreased with 
increasing myristic acid concentrations, until at $\sim 500 \mu \mathrm{M}$ myristic acid the activity levelled off to about $12 \%$. Based on this analysis, the turning point, i.e., the $\mathrm{IC}_{50}$, is at approximately $200 \mu \mathrm{M}$ myristic acid. Furthermore, these results additionally indicate that myristic acid is not a BmrA substrate that stimulates the ATPase activity, as has been observed with other $\mathrm{ABC}$ transporter substrates [17-19].

Nevertheless, the concentration for free myristic acid within the membrane is low in vivo, as myristic acid typically is part of diacylglycerol lipids. This now raised the question whether the ATPase activity of BmrA is also affected by myristic acid-containing phospholipids. Thus, we next tested the in vitro ATPase activity of isolated BmrA in the presence of increasing concentrations of 1,2-dimyristoyl-sn-glycero-3-phosphocholine (DMPC, Figure 1b,c black). DMPC is a glycerophospholipid, containing two myristic acids as fatty acids attached to the glycerol backbone. As the determined ATPase activity of BmrA is not significantly affected by DMPC, the inhibitory effects observed before can clearly be linked to the isolated myristic acid.

\subsection{The Stability of BmrA in Micelles Is Not Affected by Myristic Acid}

Myristic acid has detergent properties and can form micelles in solution [20]. As harsh detergents can unfold (membrane) proteins [21], at least to some extent, the question arose whether myristic acid does not inhibit the BmrA ATPase activity via binding but via denaturation of the protein structure, resulting in a diminished protein activity.

As changes in a local tryptophan environment, e.g., caused by protein denaturation, result in a different fluorescence emission spectrum, the stability of purified BmrA in DDM micelles can be determined by fluorescence spectroscopy. A well-established approach to unfold membrane proteins is to solubilize the protein in a mild detergent, such as DDM, and to subsequently titrate in increasing amounts of a harsh detergent, typically SDS [22,23]. Addition of SDS results in formation of mixed DDM/SDS micelles, which eventually unfold $\alpha$-helical membrane proteins. It is noteworthy that, while the mixed micelles can indeed unfold soluble regions or domains of membrane proteins, the membrane integral protein parts typically retain their helical structure, and the term "unfolding" here in fact describes the separation of previously interacting individual TM $\alpha$-helices [24].

When the purified protein was exposed to increasing SDS concentrations, the average emission wavelength $(<\lambda>)$ decreased (Figure 2, black). At a low SDS mole fraction of $\chi_{\text {SDS }}$ $=0.04$ the $<\lambda>$ slightly increased, a behavior also observed with other TM proteins [25], whereas higher SDS concentrations led to a dramatic decrease in the average emission wavelength. In contrast, while addition of low myristic acid concentration also resulted in a slight increase in the $\langle\lambda\rangle$, further increasing the myristic acid concentration resulted in a slightly decrease, albeit the $\langle\lambda>$ myristic acid never changed to an extent as observed with SDS. This indicates that myristic acid does not substantially destabilize the protein, in contrast to SDS.

\subsection{Myristic Acid Inhibits the BmrA-Mediated Transport of Hoechst 33342 in Inverted Membrane Vesicles}

Hoechst 33342 is a substrate commonly used when the BmrA activity is studied in inverted membrane vesicles. Upon spontaneous membrane partitioning, the dye's fluorescence increases. When the dye is actively transported out of the lipid membrane by BmrA and expelled to the liquid surrounding, the fluorescence decreases again. Importantly, the transport of Hoechst 33342 depends on the BmrA ATPase activity [11].

At first, the initial fluorescence of the inverted membrane vesicles was monitored in absence of Hoechst 33342 (Figure 3a). Subsequently, upon addition (Figure 3a, 1) and membrane incorporation of Hoechst 33342, the fluorescence increased tremendously due to membrane partitioning of the dye [26]. After addition of ATP the fluorescence intensity decreased again due to the removal of Hoechst 33342 from the membrane. The decrease in the fluorescence intensity thus directly correlates with the BmrA transport activity [26]. When the BmrA-mediated Hoechst 33342 transport was measured in inverted membrane vesicles pre-incubated with myristic acid, the initial fluorescence intensities were similar. 
Upon ATP addition (Figure 3a, 2), the fluorescence intensity first decreased, as observed in absence of myristic acid, yet remained on a higher fluorescence level. This implies that more Hoechst 33342 molecules remained incorporated within the lipid bilayer, and thus, less Hoechst 33342 molecules were transported by the ABC transporter (Figure 3a, red). For comparison, the absolute value of the slope was used to quantify the transport activity. The BmrA wild type transport activity was set as $100 \%$ and the generated values at increasing myristic acid concentrations were normalized to the wild type (Figure $3 b$ ).

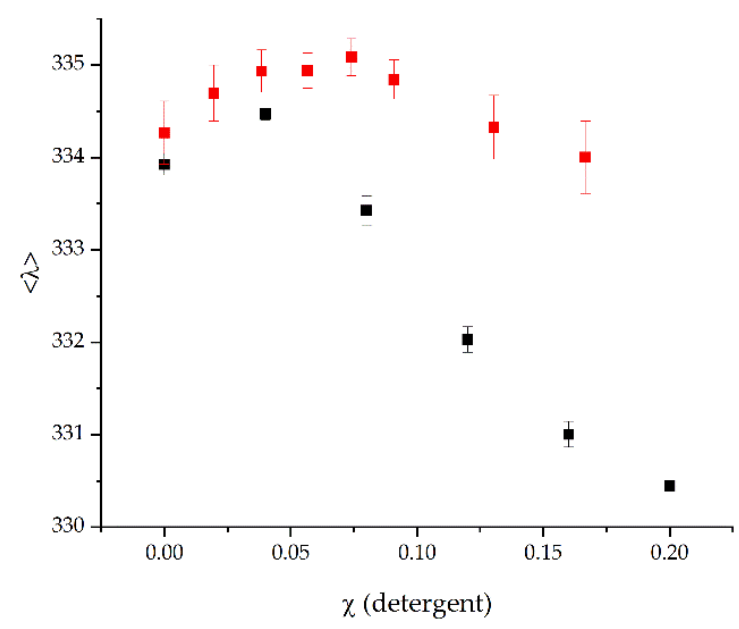

Figure 2. Myristic acid does not destabilize the BmrA structure as SDS. Increasing amounts of myristic acid ( $n=9, \pm$ SEM; red) or SDS ( $n=7, \pm$ SEM black) were titrated to BmrA solubilized in DDM micelles. While addition of SDS leads to a larger decrease in the average emission wavelength $(<\lambda>)$, this was not observed when myristic acid was added.
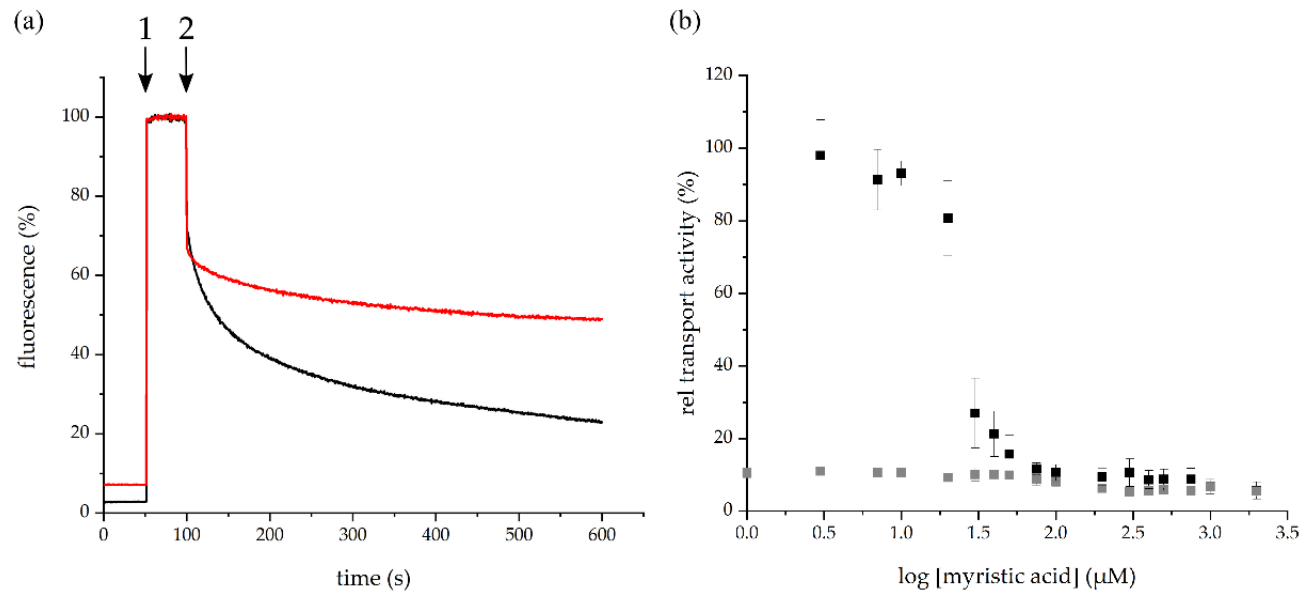

Figure 3. Myristic acid inhibits Hoechst 33342 transport in inverted C41 (DE3) E. coli membrane vesicles. (a) Kinetics of Hoechst 33342 transport followed in absence (black) or presence of $1000 \mu \mathrm{M}$ myristic acid (red), 1: addition of Hoechst 33342, 2: addition of ATP. (b) 3-1000 $\mu \mathrm{M}$ myristic acid was added to inverted membrane vesicles prepared from BmrA expressing cells (black) or E. coli C41(DE3) cells transformed with an empty vector (grey) and Hoechst 33342 transport was quantified $(n=3, \pm$ SEM).

To test a (potential) inhibition of the BmrA transport activity, myristic acid was added to inverted membrane vesicles at increasing concentrations $(3-1000 \mu \mathrm{M})$ and the Hoechst 33342 transport was quantified (Figure 3b). The BmrA transport activity was essentially not affected up to myristic acid concentrations of $10 \mu \mathrm{M}$. However, at 20-50 $\mu \mathrm{M}$ myristic acid, the transport activity of BmrA massively decreased, and at around $100 \mu \mathrm{M}$ myristic acid 
a plateau was reached. Based on a Boltzmann fit, an $\mathrm{IC}_{50}$ value of about $25 \mu \mathrm{M}$ myristic acid was determined for the Hoechst transport using inverted vesicles. As expected, the inverted vesicles prepared from E. coli C41(DE3) cells transformed with an empty vector did not show activity at any given myristic acid concentration.

Yet, myristic acid might not inhibit the BmrA transport activity, but in fact is a substrate that simply competes with Hoechst 33342 for transport. To test this assumption, inverted vesicles were first exposed to $0.2 \mathrm{mM}$ myristic acid, and the Hoechst 33342 transport was measured as before, but at different Hoechst 33342 concentrations. Upon addition of ATP, the absolute value of the slope of the fluorescence decrease was determined at each Hoechst 33342 concentration (Figure 4). When Hoechst 33342 and myristic acid compete for transport, addition of small amounts of Hoechst 33342 should not result in a measurable transport activity, and only at rather high Hoechst 33342 concentrations is an activity expected to be observed. As can be seen in Figure 4, the absolute value of the slope increased linearly with increasing Hoechst 33342 concentrations for the control (no myristic acid). In contrast, the activity of the inverted vesicles containing a constant myristic acid concentration but increasing Hoechst 33342 concentrations increased linearly up to a concentration of $\sim 0.6 \mu \mathrm{M}$ Hoechst 33342. At higher Hoechst 33342 concentrations, the initial slope remained more or less constant. If Hoechst 33342 and myristic acid were both substrates competing for binding and translocation, an initial significantly slowed down Hoechst 33342 transport would be expected at the (high) constant myristic acid concentration. However, this was not observed. Instead, the transport activity leveled off at a rather low Hoechst concentration. Consequently, the data indicate that there is no simple competitive or non- or uncompetitive inhibition of BmrA by myristic acid. The BmrA activity is inhibited by myristic acid via a rather complex mechanism. Noteworthy, the fluorescence intensities (without ATP added) of the control and the myristic acid-incubated inverted vesicles were more or less equal for each Hoechst 33342 concentration. The increasing amounts of Hoechst 33342 lead to a linearly increasing slope (data not shown).

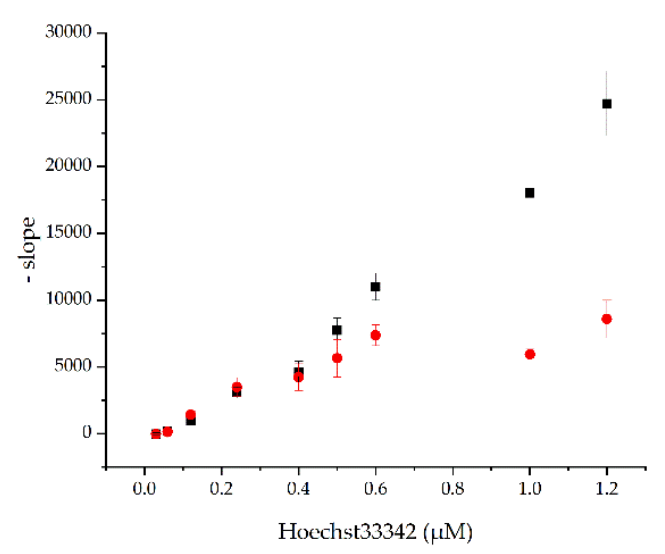

Figure 4. BmrA-mediated Hoechst 33342 transport at a constant myristic acid concentration. $0.2 \mathrm{mM}$ myristic acid (red) or methanol (control; black) were added to inverted membrane vesicles and Hoechst 33342 transport was tested at increasing Hoechst 33342 concentrations $(n=3, \pm$ SEM).

\subsection{Myristic Acid Does Not Solubilize Overexpressed BmrA in Inverted Vesicles}

Due to the detergent properties of myristic acid, it was possible that the fatty acid solubilized the overexpressed protein in the inverted vesicles, resulting in the observed decreased BmrA transport activity. To finally exclude this, vesicles were incubated with the detergent SDS or myristic acid for $1 \mathrm{~h}$. Subsequently, solubilized protein was separated from membranes via ultracentrifugation, and solubilized proteins were analyzed via SDS PAGE. As can be seen in Figure 5, while BmrA was properly solubilized by SDS, neither at low nor at high myristic acid concentrations BmrA was extracted from the membranes. Thus, the inverted vesicles remained intact at the here analyzed myristic acid concentrations. 


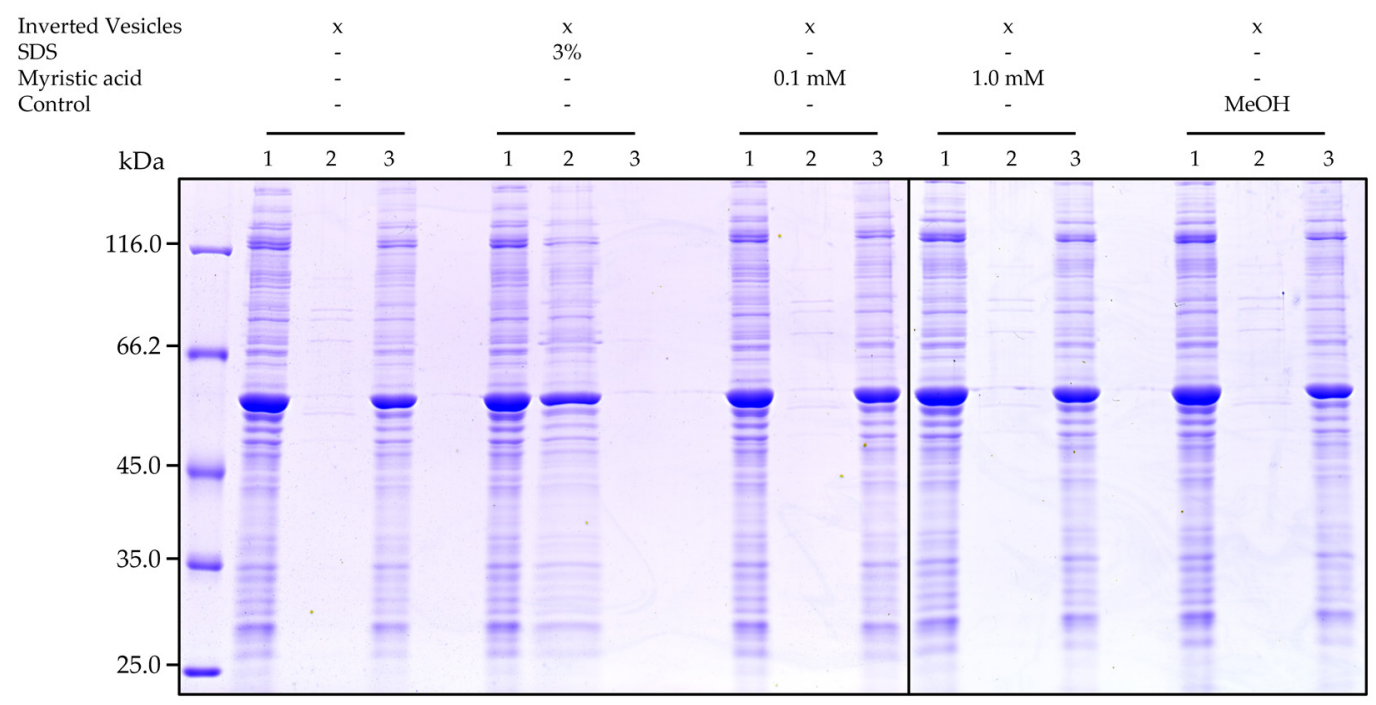

Figure 5. Stability of inverted membrane vesicles with overexpressed BmrA. Inverted vesicles were exposed to either SDS $(3 \%(w / v)$, myristic acid $(0.1 \mathrm{mM}$ or $1.0 \mathrm{mM}$ dissolved in methanol) or methanol $(0.5 \%(v / v)$. Intact membranes were found in the pellet, whereas solubilized membrane proteins were found in the supernatant (solely when SDS was added). 1: BmrA and membrane proteins in inverted vesicles not influenced by any substances. 2: Supernatant after ultracentrifugation containing solubilized BmrA (and other membrane proteins). 3: Pellet after ultracentrifugation comprising of inverted vesicles with overexpressed BmrA. This experiment was performed three times with three different inverted membrane vesicle preparations, which all showed the same results.

\section{Discussion}

In the present study, we identified myristic acid as a potential inhibitor of the BmrA ATPase and transport activity. This saturated C14 fatty acid (Figure 1a) is widely distributed in plant and animal fat and can naturally be found in high concentrations in coconut oil as well as in butter fat. Furthermore, myristic acid is utilized in the food industry as multifunctional food additive and flavor excipient [27]. In Bacillus subtilis, around 3.6\% of all lipids are myristic acid [28]. Yet, myristic acid inhibits the BmrA activity exclusively as a free acid, but not when part of phospholipids (Figure 1c, black). Thus, while $3-4 \%$ of all lipids in Bacillus subtilis are myristic acid, most of these will be part of di- or even triacylglycerols and thus the concentration of the inhibiting species, i.e., the free acid, will be low.

As we have shown here, myristic acid does neither inhibit the BmrA activity indirectly, via destabilizing membranes and extracting the protein from membranes (Figure 5), nor via detergent-induced denaturation of the protein (Figure 2). Thus, myristic acid appears to directly inhibit the BmrA ATPase and transport activities (Figures 1c and 3b), albeit the inhibitory mechanism appears to be complex.

It is well known that, e.g., the detergent Triton X-100 stimulates the ATPase activity of the ABC transporter P-glycoprotein [29], and based on this and other observations, it has been concluded that detergents can serve as P-glycoprotein substrates [30]. In many cases, addition of substrate even increases the ATPase activity of $A B C$ transporters, which was, however, not observed here. $\mathrm{ABC}$ transporter substrates have rather diverse structures [11], and also fatty acids are transported by $\mathrm{ABC}$ transporters [31]. This has been shown for some $\mathrm{ABC}$ transporters, such as MsbA or LmrA [32,33]. When the lipid A ABC transporter MsbA was heterologously expressed in L. lactis cells, it has been observed that myristic acid might be transported due to no change in the determined $\mathrm{IC}_{50}$ value [33]. Yet, based on the results presented here (Figure 4), myristic acid appears not to simply compete with Hoechst 33342 for the substrate binding site and transport.

But why is the determined $\mathrm{IC}_{50}$ value so much higher when the ATPase activity was monitored than when the transport activity was monitored? Although we cannot ultimately answer this question, these two measurements can only be compared to some extent. While 
we have a well-defined protein and detergent concentration when the isolated protein was analyzed, this was not the case in the inverted vesicles. Furthermore, in inverted vesicles we might have other components that interact with myristic acid. Yet, this would probably reduce, and not increase, the inhibitory activity of myristic acid. In bacterial membranes, most membrane lipids are not part of bulk lipids, but are (more or less tightly) bound to membrane proteins (reviewed [34]). Thus, the concentration of myristic acid added to the lipid phase is probably much higher at any given total myristic acid concentration, compared to the situation in micelles. In the latter, the myristic acid will incorporate into free micelles as well as into BmrA-containing micelles to form mixed micelles. Thus, myristic acid is likely highly diluted in the micellar system, which results in a rather high $\mathrm{IC}_{50}$ value for the determined ATPase activity. Finally, it is also possible that myristic acid induces a conformational change or decoupling of the NBD and TMD in the lipid environment, as e.g., observed with the mutant BmrA E474R [35].

\section{Materials and Methods}

\subsection{Screening for BmrA Inhibitors using Fungal Extracts and Isolation of Myristic Acid from} IBWF 030-11

448 fungal extracts dissolved in DMSO were tested in 384 well plate format in accordance to assay methodology described in 4.6 at a concentration of $0.5 \mathrm{mg} / \mathrm{mL}$ in initial screens. NADH decrease was monitored with a multilabel reader (Perkin Elmer Envision 2104). Among the active extracts was one isolated from the mycelium of strain IBWF 030-11 (Clavicipitaceae). This strain is deposited in the strain collection at the Institut für Biotechnologie und Wirkstoff-Forschung (IBWF), Mainz. The active principle was identified by subfractionation of the initial extract and retesting whereby the activity was tracked to a natural product which was unknown to the IBWF compound library. To isolate the active principle for structure elucidation and natural product characterization, strain IBWF 030-11 was regrown and cultivated in a $20 \mathrm{~L}$ fermenter in YMG medium (YMG: 4 g yeast extract, $10 \mathrm{~g}$ malt extract, $10 \mathrm{~g}$ glucose, $\mathrm{pH}$ was adjusted to 5.5 before autoclaving). For inoculation, a well-grown flask culture in the same medium was used. The mycelium was separated from the culture by filtration 16 days after inoculation, freeze-dried (dry weight $122 \mathrm{~g}$ ) and subsequently extracted with $\mathrm{MeOH}$ to yield $24 \mathrm{~g}$ crude extract. Flash chromatography on silica gel 60 (0.04-0.063 mm; Macherey-Nagel) yielded a subfraction $(750 \mathrm{mg})$ which was applied to a second silica gel fractionation to yield intermediate $1(628 \mathrm{mg})$. Preparative HPLC (PrepHT Zorbax Eclipse XDB-Phenyl, $5 \mu \mathrm{m}, 21 \times 250 \mathrm{~mm}$, Agilent Technologies, MeCN: $0.1 \%$ TFA in $\mathrm{H}_{2} \mathrm{O}$ gradient from $50 \% \mathrm{MeCN}$ to $70 \% \mathrm{MeCN}$ in $20 \mathrm{~min}, 21 \mathrm{~mL} / \mathrm{min}$ ) of intermediate 1 yielded $5 \mathrm{mg}$ of the active substance (myristic acid (RT $11.5 \mathrm{~min}$ )). The purity of the active substance was checked with mass spectrometry.

\subsection{NMR Analysis}

Myristic acid was identified by ${ }^{1} \mathrm{H},{ }^{13} \mathrm{C}, \mathrm{COSY}, \mathrm{HSQC}$, and $\mathrm{HMBC}$ NMR using a Bruker Avance III $600 \mathrm{MHz}$ spectrometer, equipped with an inverse Helium-cooled cryoprobe. All shifts are given relative to TMS, using the residual $\mathrm{CHCl}_{3}$ shift as reference $(7.26 \mathrm{ppm})$ [36].

${ }^{1} \mathrm{H}$ NMR $\left(600 \mathrm{MHz}, \mathrm{CDCl}_{3}\right) \delta=2.36(\mathrm{t}, J=7.5 \mathrm{~Hz}, 2 \mathrm{H}, \mathrm{H}-2), 1.63$ (pseudo quin, $J=7.5 \mathrm{~Hz}, 2 \mathrm{H}, \mathrm{H}-3$ ), $1.44-1.19$ (m, 20H, H-4 to H-13), 0.88 (dist. t, $J=6.9 \mathrm{~Hz}, 3 \mathrm{H}, \mathrm{H}-14$ ) ppm. ${ }^{13} \mathrm{C}$ NMR $\left(151 \mathrm{MHz}, \mathrm{CDCl}_{3}\right) \delta=176.6^{*}(\mathrm{C}-1$, by HMBC), 33.4 (C-2), 31.9 (C-12), 29.8-29.0 (C-4 to C-11), 24.7 (C-3), 22.7 (C-13), 14.2 (C-14) ppm. Shifts are in accordance with the literature [37].

\subsection{Cloning}

The Bacillus subtilis bmrA gene was amplified via PCR from genomic B. subtilis (strain 168) DNA using the following primers:

Forward: 5' GCTACCTCTAGAATGCCAACCAAGAAACAAAAATCTAAAAG $3^{\prime}$ and reverse: 5' GCTATTCTCGAGCCCGGCTTTGTTTTCTAAG 3'. 
The PCR product was cloned into the plasmid pET303-CT/His (Invitrogen, Carlsbad, CA, USA), whereby the $3^{\prime}$ end was extended by a sequence coding for a short linker and a $\mathrm{His}_{6}$-tag.

\subsection{Expression}

The pET303-CT/His-BmrA plasmid was transformed in competent BL21(DE3) pLysE E. coli cells, and cells were subsequently plated on LB agar containing $100 \mu \mathrm{g} / \mathrm{mL}$ ampicillin. A single colony was used to inoculate an overnight culture, which was used the next morning to inoculate a $2 \mathrm{~L}$ culture, containing $100 \mu \mathrm{g} / \mathrm{mL}$ ampicillin and $30 \mu \mathrm{g} / \mathrm{mL}$ chloramphenicol. The cells were cultivated at $37{ }^{\circ} \mathrm{C}$ with constant agitation $(150 \mathrm{rpm})$. When the culture reached an $\mathrm{OD}_{600}$ of $\sim 0.8$, protein expression was induced via addition of isopropyl- $\beta$-D-thiogalacto-pyranoside (IPTG) to a final concentration of $0.5 \mathrm{mM}$. Cells were harvested after $3-4 \mathrm{~h}$ via centrifugation $\left(3050 \times \mathrm{g}, 10 \mathrm{~min}\right.$ at $\left.4{ }^{\circ} \mathrm{C}\right)$. The cell pellets then were stored at $-20^{\circ} \mathrm{C}$.

\subsection{Purification}

The cell pellets were resuspended in $50 \mathrm{mM}$ phosphate buffer ( $\mathrm{pH} 8.0), 300 \mathrm{mM} \mathrm{NaCl}$, $10 \%$ glycerol $(v / v)$ and lysed using a microfluidizer (LM20, Microfluidics, Westwood, CA, USA, $18000 \mathrm{PSi})$. After centrifuging at $12,075 \times g\left(10 \mathrm{~min}\right.$ at $\left.4{ }^{\circ} \mathrm{C}\right)$, the supernatant was centrifuged again at $165,000 \times g$ for $1 \mathrm{~h}$ at $4{ }^{\circ} \mathrm{C}$ to isolate membranes. The membranes were solubilized in solubilization buffer ( $50 \mathrm{mM}$ phosphate buffer $(\mathrm{pH} 8.0), 300 \mathrm{mM} \mathrm{NaCl}, 10 \%$ glycerol $(v / v)$ with $1 \% n$-dodecyl- $\beta$-D-maltoside (DDM) $(w / v))$ to extract the membraneincorporated proteins. After $1 \mathrm{~h}$ of incubation, insolubilized protein was removed by centrifugation $(165,000 \times g, 20 \mathrm{~min})$ and the equilibrated Protino ${ }^{\circledR}$ Ni-NTA agarose $(2 \mathrm{~mL}$ resin/L of E. coli culture; Macherey-Nagel GmbH \& Co. KG, Düren, Germany) was mixed with the solubilized proteins and incubated for $1 \mathrm{~h}$. After washing the Ni-NTA agarose with $20 \mathrm{~mL}$ washing buffer (50 mM phosphate buffer ( $\mathrm{pH} 8.0$ ), $300 \mathrm{mM} \mathrm{NaCl}, 10 \%$ glycerol $(v / v)$ with $0.1 \% \operatorname{DDM}(w / v)$ and $40 \mathrm{mM}$ imidazole), the protein was eluted with $5 \mathrm{~mL}$ elution buffer (50 mM phosphate buffer ( $\mathrm{pH} 8.0), 300 \mathrm{mM} \mathrm{NaCl}, 10 \%$ glycerol $(v / v)$ with $0.1 \% \operatorname{DDM}(w / v)$ and $400 \mathrm{mM}$ imidazole). To exchange the buffer to the required assay buffer (containing 5 mM DDM), a PD-10 desalting column (Macherey-Nagel GmbH \& Co. KG, Düren, Germany) was utilized. The concentration of the purified membrane protein BmrA was determined photometrically by measuring the absorbance at $280 \mathrm{~nm}$ and the calculated extinction coefficient $\varepsilon=38850 \mathrm{M}^{-1} \mathrm{~cm}^{-1}$.

\subsection{ATPase Activity of Purified BmrA}

The ATPase activity of $0.2 \mu \mathrm{M}$ protein BmrA was measured in DDM micelles at $25^{\circ} \mathrm{C}$ in $50 \mathrm{mM}$ Hepes-KOH (pH 8.0 and $5 \mathrm{mM}$ DDM) with $3.5 \mathrm{mM} \mathrm{ATP}, 10 \mathrm{mM} \mathrm{MgCl}{ }_{2}$, $0.28 \mathrm{mM}$ NADH, $2 \mathrm{mM}$ phosphoenolpyruvate, by adding $2 \mu \mathrm{L}$ of pyruvate kinase (600-1000 U/mL)/lactate dehydrogenase (900-1400 U/mL) mix to the $200 \mu \mathrm{L}$ test volume. Absorption changes were measured at a wavelength of $340 \mathrm{~nm}$ and a slit width of $4 \mathrm{~nm}$ using a Lambda $35 \mathrm{U} V / V$ is spectrophotometer (PerkinElmer, Inc., Waltham, MA, USA). Here the usage of NADH was monitored. The NADH decrease was measured for $180 \mathrm{sec}$ and converted into the BmrA activity in $\min ^{-1}$.

$$
\text { ATPase activity }=-\frac{\Delta A_{340}}{\Delta t} \cdot \frac{1}{l \cdot \varepsilon_{N A D H}} \cdot M W_{B m r A} \cdot \frac{1}{c_{B m r A}}
$$

Equation (1) comprises of the slope $\left(\frac{\Delta A_{340}}{\Delta t}\right)$ of the NADH decrease, the optical pathlength $(l \mathrm{in} \mathrm{cm})$, the extinction coefficient of NADH $\left(\varepsilon_{\mathrm{NADH}}=6220 \mathrm{M}^{-1} \mathrm{~cm}^{-1}\right)$ as well as of the calculated molecular weight of BmrA $(65584.27 \mathrm{~g} / \mathrm{mol})$ and the used BmrA concentration $\left(c_{B m r A}\right.$ in $\left.g / L\right)$. The ATPase activity without substance was set as $100 \%$ and the data points measured at different myristic acid and DMPC concentrations were normalized to this level with respect to the error propagation. 
For the experiments (except for the screening and NMR), commercially available myristic acid (Sigma-Aldrich, Merck KGaA, Darmstadt, Germany, M3128) with a high purity ( $\geq 99 \%$ ) was used. Myristic acid (dissolved in methanol) or 1,2-dimyristoyl-snglycero-3-phosphocholin (DMPC; solved in chloroform) was pipetted at the specified amounts into the reaction tubes. Subsequently, the solvent was removed by a constant stream of nitrogen, and these reaction tubes were further stored for at least $30 \mathrm{~min}$ under vacuum. The dried fatty acid was dissolved in sample buffer (50 mM Hepes- $\mathrm{KOH}, \mathrm{pH}$ 8.0, $5 \mathrm{mM}$ DDM) and the solution was vortexed and further incubated for at least $1 \mathrm{~h}$ under constant agitation (500 rpm). Thereafter, the protein was added, and the solution incubated for another $10 \mathrm{~min}$ at $25^{\circ} \mathrm{C}$. After adding the other compounds to the solution, the decrease in absorbance was immediately monitored.

\subsection{Hoechst 33342 Transport Measured Using BmrA-Containing Inverted E. coli Membrane Vesicles}

Inverted E. coli membrane vesicles were prepared as described in Steinfels et al., 2002 [38], except that a microfluidizer was used at 18000 Psi instead of a French press.

The membrane protein concentration was determined with a BCA assay $\left(\right.$ Pierce $^{\mathrm{TM}}$ BCA protein assay kit, Thermo Fisher Scientific, Rockford, IL, USA), following the vendor's instructions. In all, $50 \mu \mathrm{g}$ of inverted membrane vesicles were dissolved in a final volume of $200 \mu \mathrm{L}$ of $50 \mathrm{mM}$ Hepes- $\mathrm{KOH}$ (pH 8.0), $2 \mathrm{mM} \mathrm{MgCl}_{2}, 8.5 \mathrm{mM} \mathrm{NaCl}, 4 \mathrm{mM}$ phosphoenolpyruvate and $20 \mu \mathrm{g} / \mathrm{mL}$ pyruvate kinase. Myristic acid (dissolved in methanol) was added to the reaction mixture at various concentrations $(3 \mu \mathrm{M}, 7 \mu \mathrm{M}, 10 \mu \mathrm{M}, 20 \mu \mathrm{M}, 30 \mu \mathrm{M}$, $40 \mu \mathrm{M}, 50 \mu \mathrm{M}, 75 \mu \mathrm{M}, 100 \mu \mathrm{M}, 200 \mu \mathrm{M}, 300 \mu \mathrm{M}, 400 \mu \mathrm{M}, 500 \mu \mathrm{M}, 750 \mu \mathrm{M}, 1000 \mu \mathrm{M})$ and following incubation for more than $10 \mathrm{~min}$. The maximal concentration of methanol in this reaction mixture was $0.5 \%(v / v)$. Fluorescence emission was measured at $457 \mathrm{~nm}$ using a FluoroMax-4 fluorometer (Horiba Instruments Inc., Edison, NY, USA) upon excitation at $355 \mathrm{~nm}$, with excitation and emission slit widths of $2 \mathrm{~nm}$ and $3 \mathrm{~nm}$, respectively. After monitoring the fluorescence for approximately $50 \mathrm{~s}$, the measurement was stopped. Then, $2 \mu \mathrm{M}$ 2'-[4-ethoxyphenyl]-5-[4-methyl-1-piperazinyl]-2,5'-bis-1H-benzimidazole (Hoechst 33342) was added and the fluorescence was measured again for approximately $50 \mathrm{~s}$. Then, ATP was added to a final concentration of $2 \mathrm{mM}$ and the fluorescence was further monitored for $\sim 500 \mathrm{~s}$. Data points were collected every $0.5 \mathrm{~s}$. The slope of the measured fluorescence intensity (after addition of ATP) was determined by fitting a linear regression line with a large coefficient of determination. Then the absolute value of the slope of the sample containing inverted membrane vesicles with overexpressed BmrA $(50 \mu \mathrm{g})$ plus methanol $(0.5 \%(v / v))$ was set as "100\% transport activity" and the data points measured at different myristic acid concentrations were normalized to this considering error propagation. All presented data are based on three independent inverted vesicle preparations, and the mean with corresponding SEM is shown.

For the competition assay, inverted membrane vesicles containing $50 \mu \mathrm{g}$ protein were incubated with $0.2 \mathrm{mM}$ myristic acid for at least $10 \mathrm{~min}$ at $25^{\circ} \mathrm{C}$. The fluorescence signal was measured as described (exception: slit width of $3 \mathrm{~nm}$ ). When the measurement was started, the fluorescence was monitored for $50 \mathrm{~s}$. Varying concentrations of Hoechst 33342 were added $(0.03 \mu \mathrm{M}, 0.06 \mu \mathrm{M}, 0.12 \mu \mathrm{M}, 0.24 \mu \mathrm{M}, 0.3 \mu \mathrm{M}, 0.4 \mu \mathrm{M}, 0.5 \mu \mathrm{M}, 0.6 \mu \mathrm{M}, 1.0 \mu \mathrm{M}$, $1.2 \mu \mathrm{M})$ and the measurement and data evaluation continued as described before.

\subsection{Destabilization of BmrA in DDM Micelles}

Purified BmrA (2 $\mu \mathrm{M})$ in $50 \mathrm{mM}$ phosphate buffer (pH 8.0), $300 \mathrm{mM} \mathrm{NaCl}, 10 \%$ glycerol $(v / v), 5 \mathrm{mM}$ DDM was mixed with increasing amounts of sodium dodecyl sulfate (SDS; concentrations: $0 \mathrm{mM}, 0.21 \mathrm{mM}, 0.43 \mathrm{mM}, 0.68 \mathrm{mM}, 0.95 \mathrm{mM}, 1.25 \mathrm{mM}$ ) or myristic acid (concentrations: $0 \mathrm{mM}, 0.1 \mathrm{mM}, 0.2 \mathrm{mM}, 0.3 \mathrm{mM}, 0.4 \mathrm{mM}, 0.5 \mathrm{mM}, 0.75 \mathrm{mM}, 1.0 \mathrm{mM}$ ). The samples were incubated at room temperature for $1 \mathrm{~h}$. Fluorescence spectra were recorded (from 290-450 nm) using a FluoroMax-4 fluorometer with $280 \mathrm{~nm}$ excitation and a slit width of $3 \mathrm{~nm}$. The average emission wavelength $(<\lambda>)$, which represents changes in shape and position of the spectrum, was used to characterize the entire measured tryptophan 
fluorescence emission spectrum. The $<\lambda>$ was calculated as described in the following Equation (2):

$$
\langle\lambda\rangle=\frac{\left(\Sigma_{i} \lambda_{i} \cdot I_{i}\right)}{\Sigma_{i} I_{i}}
$$

Here $\lambda$ is the wavelength in $\mathrm{nm}$ and $I$ is the fluorescence intensity.

\subsection{Stability of BmrA in Inverted Vesicles}

Inverted vesicles $(250 \mu \mathrm{g} / \mathrm{mL})$ were incubated with either $0.1 \mathrm{mM}$ or $1.0 \mathrm{mM}$ myristic acid for $1 \mathrm{~h}$ at room temperature at constant agitation. As a control, $0.5 \%(v / v)$ methanol was added to inverted vesicles. As a second control, vesicles were incubated with $3 \%$ $\operatorname{SDS}(w / v)$. After incubation, the samples were centrifuged at $140,000 \times g$ for $1 \mathrm{~h}$ at $25^{\circ} \mathrm{C}$. Samples were taken before incubation with the substances and after centrifugation (from the supernatant as well as the pellet). A total of $10 \mu \mathrm{L}$ of each sample was analyzed on a $10 \%$ SDS PAGE gel.

\section{Conclusions and Implications}

At first, inhibition of an $\mathrm{ABC}$ transporter activity by a naturally occurring fatty acid appears to be unexpected, albeit the physiological concentration of myristic acid in Bacillus subtilis membranes is probably not sufficiently high to compromise the BmrA transport activity. However, it might even be beneficial to inhibit a basal ATPase activity, by which ATP might be wasted in cells, in vivo using naturally occurring membrane incorporated substances, such as myristic acid.

The initial idea of this project was to identify potential modulators of the BmrA activity. Based on the presented results myristic acid might qualify as a drug excipient, as co-application with $\mathrm{ABC}$ transporter substrates might reduce the risk of drug export out of a cell. Furthermore, as mentioned in the discussion, myristic acid is used as a multifunctional food additive and flavor excipient [27]. Thus, this food additive has the potential to interfere with (human) $A B C$ transporters, an aspect which, to the best of our knowledge, has never been discussed thus far and which we will explore in future experiments.

Author Contributions: Conceptualization, K.O., A.S. and D.S.; methodology, K.O., J.C.L. and H.Ö.; validation, K.O., J.C.L., H.Ö. and A.S.; formal analysis, K.O., A.S. and D.S.; investigation, K.O., J.C.L. and H.Ö.; resources, E.T. and D.S.; writing —original draft preparation, K.O. and D.S.; writingreview and editing, K.O. and D.S.; visualization, K.O. and D.S.; supervision, A.S., E.T. and D.S.; project administration, E.T. and D.S.; funding acquisition, E.T. and D.S. All authors have read and agreed to the published version of the manuscript.

Funding: This work was supported by the Naturwissenschaftlich-Medizinisches Forschungszentrum (NMFZ) Mainz and by DynaMem (State of Rhineland-Palatinate).

Institutional Review Board Statement: Not applicable.

Informed Consent Statement: Not applicable.

Data Availability Statement: The data presented in this study are available on request from the corresponding author.

Acknowledgments: We thank G. Unden for providing the B. subtilis strain 168 and N. Hellmann for discussion and proof reading.

Conflicts of Interest: The authors declare no conflict of interest.

\section{References}

1. Wilkens, S. Structure and Mechanism of ABC Transporters. F1000Prime Rep. 2015, 7, 1-9. [CrossRef] [PubMed]

2. Hediger, M.A.; Romero, M.F.; Peng, J.-B.; Rolfs, A.; Takanaga, H.; Bruford, E.A. The ABCs of Solute Carriers: Physiological, Pathological and Therapeutic Implications of Human Membrane Transport Proteins. Pflugers Arch. Eur. J. Physiol. 2004, 447, 465-468. [CrossRef] [PubMed]

3. Higgins, C.F. ABC Transporters: From Microorganisms to Man. Annu. Rev. Cell Biol. 1992, 8, 67-113. [CrossRef] [PubMed] 
4. Hanekop, N.; Zaitseva, J.; Jenewein, S.; Holland, I.B.; Schmitt, L. Molecular Insights into the Mechanism of ATP-Hydrolysis by the NBD of the ABC-Transporter HlyB. FEBS Lett. 2006, 580, 1036-1041. [CrossRef] [PubMed]

5. Holland, I.B.; Blight, M.A. ABC-ATPases, Adaptable Energy Generators Fuelling Transmembrane Movement of a Variety of Molecules in Organisms from Bacteria to Humans. J. Mol. Biol. 1999, 293, 381-399. [CrossRef]

6. Dalmas, O.; Do Cao, M.-A.; Lugo, M.R.; Sharom, F.J.; Di Pietro, A.; Jault, J.-M. Time-Resolved Fluorescence Resonance Energy Transfer Shows That the Bacterial Multidrug ABC Half-Transporter BmrA Functions as a Homodimer. Biochemistry 2005, 44, 4312-4321. [CrossRef]

7. Falasca, M.; Linton, K.J. Investigational ABC Transporter Inhibitors. Expert Opin. Investig. Drugs 2012, 21, 657-666. [CrossRef]

8. Smith, P.C.; Karpowich, N.; Millen, L.; Moody, J.E.; Rosen, J.; Thomas, P.J.; Hunt, J.F. ATP Binding to the Motor Domain from an ABC Transporter Drives Formation of a Nucleotide Sandwich Dimer. Mol. Cell 2002, 10, 139-149. [CrossRef]

9. Neyfakh, A.A.; Bidnenko, V.E.; Chen, L.B. Efflux-Mediated Multidrug Resistance in Bacillus Subtilis: Similarities and Dissimilarities with the Mammalian System. Proc. Natl. Acad. Sci. USA 1991, 88, 4781-4785. [CrossRef]

10. Krügel, H.; Licht, A.; Biedermann, G.; Petzold, A.; Lassak, J.; Hupfer, Y.; Schlott, B.; Hertweck, C.; Platzer, M.; Brantl, S.; et al. Cervimycin C Resistance in Bacillus Subtilis Is Due to a Promoter Up-Mutation and Increased MRNA Stability of the Constitutive ABC-Transporter Gene BmrA. FEMS Microbiol. Lett. 2010, 313, 155-163. [CrossRef]

11. Steinfels, E.; Orelle, C.; Fantino, J.-R.; Dalmas, O.; Rigaud, J.-L.; Denizot, F.; Di Pietro, A.; Jault, J.-M. Characterization of YvcC (BmrA), a Multidrug ABC Transporter Constitutively Expressed in Bacillus Subtilis. Biochemistry 2004, 43, 7491-7502. [CrossRef]

12. Chami, M.; Steinfels, E.; Orelle, C.; Jault, J.-M.; Di Pietro, A.; Rigaud, J.-L.; Marco, S. Three-Dimensional Structure by Cryo-Electron Microscopy of YvcC, an Homodimeric ATP-Binding Cassette Transporter from Bacillus Subtilis. J. Mol. Biol. 2002, 315, 1075-1085. [CrossRef] [PubMed]

13. Lacabanne, D.; Lends, A.; Danis, C.; Kunert, B.; Fogeron, M.L.; Jirasko, V.; Chuilon, C.; Lecoq, L.; Orelle, C.; Chaptal, V.; et al. Gradient Reconstitution of Membrane Proteins for Solid-State NMR Studies. J. Biomol. NMR 2017, 69, 81-91. [CrossRef] [PubMed]

14. Hunter, A.D. ACD/ChemSketch 1.0 (Freeware); ACD/ChemSketch 2.0 and Its Tautomers, Dictionary, and 3D Plug-Ins; ACD/HNMR 2.0; ACD/CNMR 2.0. J. Chem. Educ. 1997, 74, 905-906. [CrossRef]

15. Ravaud, S.; Do Cao, M.A.; Jidenko, M.; Ebel, C.; Le Maire, M.; Jault, J.M.; Di Pietro, A.; Haser, R.; Aghajari, N. The ABC Transporter BmrA from Bacillus Subtilis Is a Functional Dimer When in a Detergent-Solubilized State. Biochem. J. 2006, 395, 345-353. [CrossRef] [PubMed]

16. Orelle, C.; Gubellini, F.; Durand, A.; Marco, S.; Lévy, D.; Gros, P.; Di Pietro, A.; Jault, J.-M. Conformational Change Induced by ATP Binding in the Multidrug ATP-Binding Cassette Transporter BmrA. Biochemistry 2008, 47, 2404-2412. [CrossRef]

17. Sharom, F.J. Characterization and Functional Reconstitution of the Multidrug Transporter. J. Bioenerg. Biomembr. 1995, 27, 15-22. [CrossRef] [PubMed]

18. Ambudkar, S.V.; Lelong, I.H.; Zhang, J.; Cardarelli, C.O.; Gottesman, M.M.; Pastan, I. Partial Purification and Reconstitution of the Human Multidrug-Resistance Pump: Characterization of the Drug-Stimulatable ATP Hydrolysis. Proc. Natl. Acad. Sci. USA 1992, 89, 8472-8476. [CrossRef]

19. de Athayde Moncorvo Collado, A.; Corbalán, N.; Homolya, L.; Morero, R.; Minahk, C. Resveratrol Modulates ATPase Activity of Liposome-Reconstituted ABCG1. FEBS Lett. 2013, 587, 2359-2363. [CrossRef] [PubMed]

20. Fameau, A.-L.; Ventureira, J.; Novales, B.; Douliez, J.-P. Foaming and Emulsifying Properties of Fatty Acids Neutralized by Tetrabutylammonium Hydroxide. Colloids Surfaces A Physicochem. Eng. Asp. 2012, 403, 87-95. [CrossRef]

21. Veerappan, A.; Cymer, F.; Klein, N.; Schneider, D. The Tetrameric $\alpha$-Helical Membrane Protein GlpF Unfolds via a Dimeric Folding Intermediate. Biochemistry 2011, 50, 10223-10230. [CrossRef]

22. Anbazhagan, V.; Cymer, F.; Schneider, D. Unfolding a Transmembrane Helix Dimer: A FRET Study in Mixed Micelles. Arch. Biochem. Biophys. 2010, 495, 159-164. [CrossRef] [PubMed]

23. Sehgal, P.; Mogensen, J.E.; Otzen, D.E. Using Micellar Mole Fractions to Assess Membrane Protein Stability in Mixed Micelles. Biochim. Biophys. Acta-Biomembr. 2005, 1716, 59-68. [CrossRef] [PubMed]

24. Hellmann, N.; Schneider, D. A Complex Unfolding Pathway of $\alpha$-Helical Membrane Proteins in SDS-Containing Micelles. Biophys. J. 2021, 120, 3857-3859. [CrossRef] [PubMed]

25. Otzen, D.E.; Nedergaard Pedersen, J.; Kumar Somavarapu, A.; Clement, A.; Ji, M.; Hartvig Petersen, E.; Skov Pedersen, J.; Urban, S.; Schafer, N.P. Cys-Labeling Kinetics of Membrane Protein GlpG: A Role for Specific SDS Binding and Micelle Changes? Biophys. J. 2021, 120, 4115-4128. [CrossRef] [PubMed]

26. Shapiro, A.B.; Ling, V. Reconstitution of Drug Transport by Purified P-Glycoprotein. J. Biol. Chem. 1995, 270, 16167-16175. [CrossRef]

27. Burdock, G.A.; Carabin, I.G. Safety Assessment of Myristic Acid as a Food Ingredient. Food Chem. Toxicol. 2007, 45, 517-529. [CrossRef] [PubMed]

28. Bishop, D.G.; Rutberg, L.; Samuelsson, B. The Chemical Composition of the Cytoplasmic Membrane of Bacillus Subtilis. Eur. J Biochem 1967, 2, 448-453. [CrossRef] [PubMed]

29. Doige, C.A.; Yu, X.; Sharom, F.J. The Effects of Lipids and Detergents on ATPase-Active P-Glycoprotein. Biochim. Biophys. Acta 1993, 1146, 65-72. [CrossRef]

30. Sharom, F.J. The P-Glycoprotein Efflux Pump: How Does It Transport Drugs? J. Membr. Biol. 1997, 160, 161-175. [CrossRef] 
31. Neumann, J.; Rose-Sperling, D.; Hellmich, U.A. Diverse Relations between ABC Transporters and Lipids: An Overview. Biochim. Biophys. Acta-Biomembr. 2017, 1859, 605-618. [CrossRef] [PubMed]

32. Reuter, G.; Janvilisri, T.; Venter, H.; Shahi, S.; Balakrishnan, L.; van Veen, H.W. The ATP Binding Cassette Multidrug Transporter LmrA and Lipid Transporter MsbA Have Overlapping Substrate Specificities. J. Biol. Chem. 2003, 278, 35193-35198. [CrossRef] [PubMed]

33. Woebking, B.; Reuter, G.; Shilling, R.A.; Velamakanni, S.; Shahi, S.; Venter, H.; Balakrishnan, L.; van Veen, H.W. Drug-Lipid A Interactions on the. J. Bacteriol. 2005, 187, 6363-6369. [CrossRef]

34. Lee, A. Lipid-Protein Interactions in Biological Membranes: A Structural Perspective. Biochim. Biophys. Acta-Biomembr. 2003, 1612, 1-40. [CrossRef]

35. Lacabanne, D.; Orelle, C.; Lecoq, L.; Kunert, B.; Chuilon, C.; Wiegand, T.; Ravaud, S.; Jault, J.M.; Meier, B.H.; Böckmann, A. Flexible-to-Rigid Transition Is Central for Substrate Transport in the ABC Transporter BmrA from Bacillus Subtilis. Commun. Biol. 2019, 2, 1-9. [CrossRef] [PubMed]

36. Gottlieb, H.E.; Kotlyar, V.; Nudelman, A. NRM Chemicals Shifts of Common Laboratory Solvents as Traces Imputities. J. Org. Chem. 1997, 62, 7512-7515. [CrossRef] [PubMed]

37. Murray, A.T.; Matton, P.; Fairhurst, N.W.G.; John, M.P.; Carbery, D.R. Biomimetic Flavin-Catalyzed Aldehyde Oxidation. Org. Lett. 2012, 14, 3656-3659. [CrossRef] [PubMed]

38. Steinfels, E.; Orelle, C.; Dalmas, O.; Penin, F.; Miroux, B.; Di Pietro, A.; Jault, J.-M. Highly Efficient Over-Production in E. Coli of YvcC, a Multidrug-like ATP-Binding Cassette Transporter from Bacillus Subtilis. Biochim. Biophys. Acta-Biomembr. 2002, 1565, 1-5. [CrossRef] 